\title{
MUJER Y CULTURAS POLÍTICAS EN EL FRANQUISMO Y EL ANTIFRANQUISMO*
}

\section{Mónica Moreno Seco}

En torno a la dictadura franquista se desarrollaron diversas culturas políticas, para legitimarla y darle sustento ideológico o para intentar derrocarla. De ellas, las dos fundamentales fueron la católica y la comunista, pues, por un lado, el falangismo fue muy dependiente en sus planteamientos teóricos del catolicismo, mientras que, por el otro, el comunismo se erigió en el eje fundamental de la resistencia antifranquista. Se trata de dos culturas políticas que partían de posiciones antagónicas, pero que se transformaron con el tiempo e incorporaron nuevas categorías discursivas y novedosas formas de actuación. La evolución en el comunismo hacia posiciones moderadas por una decidida voluntad de consenso con las fuerzas de la oposición y sobre todo la profunda revisión del discurso católico con el Concilio Vaticano II hicieron posible la aproximación e incluso la colaboración en la lucha antifranquista entre comunistas y grupos cristianos de base. Estas culturas políticas renovadas contribuyeron además a democratizar la sociedad, demostrando que existía una pluralidad de propuestas y promoviendo una mayor movilización de ciudadanas y ciudadanos ${ }^{1}$. No puede negarse que existieron tensiones entre estos distintos discursos, e incluso entre discursos y prácticas -que muchas veces, aunque no siempre, reprodujeron desencuentros entre hombres y mujeres, entre veteranos y jóvenes, incluso entre clases sociales-. Pero tampoco, y es lo que desea resaltar este texto, que los planteamientos y experiencias de católicas y comunistas posibilitaron una confluencia de intereses en torno a la

\footnotetext{
* Este trabajo se enmarca en el Proyecto GV06/218.

1. Como propone para otra época Miguel GonZÁlez, Román, «Las culturas políticas del republicanismo histórico español», Ayer, no 53 (2004), pp. 231-232.
} 
defensa de la democracia y del feminismo, que contribuyeron a afianzar el proceso de transición y una mejora en la situación de las españolas.

En las primeras décadas de la dictadura, catolicismo y comunismo pertenecían a universos culturales y políticos opuestos, como se había hecho evidente en la Guerra Civil. En realidad, este enfrentamiento hundía sus raíces en tiempos anteriores, en el siglo XIX y en la pugna clericalismo-anticlericalismo de las primeras décadas del $\mathrm{XX}^{2}$. El discurso católico tradicional reproducía un ideal de la domesticidad que concebía a la mujer como eje de la vida familiar, limitaba su trayectoria vital a las tareas de madre y esposa, aunque es cierto que le reservaba una misión religiosa en la familia, que se proyectó en una activa función social y política ${ }^{3}$. Por su parte, en el discurso obrerista, antecedente del comunista, se planteaba la igualdad entre mujeres y hombres, pero se consideraba que los problemas de las mujeres desaparecerían con el fin del capitalismo y la instauración de una futura sociedad socialista, por lo que con frecuencia se postergaba la conquista de los derechos de las mujeres a la revolución social. No obstante, no pueden olvidarse interesantes propuestas teóricas, como las planteadas por la socialista María Cambrils, o la libertaria Teresa Claramunt, entre otras, que reclamaban una atención específica a las necesidades de las trabajadoras ${ }^{4}$.

En las primeras décadas de la dictadura, las culturas políticas franquistas se inspiraban en la doctrina católica, a la que se remitían en esencia los planteamientos falangistas sobre la mujer ${ }^{5}$. La legislación franquista, la Sección Femenina y la Iglesia católica coincidieron en un modelo de mujer religiosa y

2. Desde una perspectiva de género, vid. SAlOMÓN CHELIz, Pilar, «¿Espejos invertidos?: mujeres clericales, mujeres anticlericales», Arenal, vol. 11, no 2 (2004), pp. 87-111 o SANFELIU, Luz, Republicanas: identidades de género en el blasquismo (1985-1910), Valencia, 2005.

3. Entre otros trabajos, vid. BlasCO, Inmaculada, Paradojas de la ortodoxia. Política de masas y militancia católica femenina en España (1919-1939), Zaragoza, 2003; GARCíA CHECA, Amelia, Ideología y práctica de la acción social católica femenina (Cataluña, 19001930), Málaga, 2007, y ARCE Pinedo, Rebeca, Dios, Patria y Hogar. La construcción social de la mujer española por el catolicismo y las derechas en el primer tercio del siglo XX, Santander, 2008.

4. Existe abundante bibliografía, de la que puede destacarse NASH, Mary, Mujer y movimiento obrero en España, 1931-1939, Barcelona, 1981; CAPEL MARTíneZ, Rosa Mª , Socialismo e igualdad de género. Un camino común, Madrid, 2007; AGUAdo HigÓN, Ana, «Feminismo socialista y/o socialismo feminista, María Cambrils», Arenal, vol. 10, no 2 (2003), pp. 243-254; ESPIGADO TOCINO, Gloria, «La mujeres en el anarquismo español (18691939)», Ayer, no 45 (2002), pp. 39-72, y VicENTE VillanUeVA, Laura, Teresa Claramunt. Pionera del feminismo obrerista anarquista, Madrid, 2006.

5. Molinero, Carme, «Mujer, franquismo, fascismo. La clausura forzada en un 'mundo pequeño'», Historia Social, nº 30 (1998), pp. 116-117. 
doméstica. El catolicismo se convirtió por tanto en el eje de la construcción de la identidad femenina, en torno a la domesticidad y a la contraposición entre María y Eva ${ }^{6}$. Los principios básicos que promovía el discurso católico sobre las mujeres se pueden resumir en: autoridad, jerarquía y sumisión al poder, ya fuera en la familia, en la sociedad o en la vida política. A las diferencias consideradas naturales entre mujeres y hombres le correspondían atribuciones de género diferenciadas, que para las mujeres significaban una insistencia en la abnegación, el sacrificio, el servicio o la obediencia, legitimando así la subordinación femenina a la autoridad masculina.

En el discurso del nacional-catolicismo, la mujer desempeñaba una función de reconquista espiritual y política, desde el ámbito doméstico, como transmisora de valores religiosos y morales en la familia. Según Di Febo, la recristianización se vinculó a la regeneración nacional, la redención moral y un orden antimoderno, proceso en el cual se atribuyó una gran relevancia a las mujeres, por lo que la identidad de género se redefinió en clave nacionalcatólica ${ }^{7}$. Se entendía el cuidado de la familia cristiana y numerosa como una tarea política y religiosa. En esta tarea de reconquista también participaron gran número de seglares -en especial de Acción Católica- y de religiosas, que si bien mantenían posiciones subordinadas y un discurso de la diferencia, ofrecían a muchas mujeres un espacio de actividad pública ${ }^{8}$. Su acción se centró en la defensa de la religión y la familia, la moral y la caridad, de acuerdo con el ideal de domesticidad del catolicismo del momento.

Frente al discurso religioso, el comunista, en pleno contexto de clandestinidad, enarboló algunos conceptos antagónicos a los anteriores: igualdad, libertad, justicia. Sin embargo, no desarrolló un discurso elaborado por y para las mujeres, lo cual puede entroncar con la Asociación de Mujeres

6. ROCA I GIRONA, Jordi, De la pureza a la maternidad. La construcción del género femenino en la posguerra española, Madrid, 1996 y «Esposa y madre a la vez. Construcción y negociación del modelo ideal de mujer bajo el (primer) franquismo», en NiELFA CRISTÓBAL, Gloria (ed.), Mujeres y hombres en la España franquista: sociedad, economía, política cultura, Madrid, 2003, pp. 45-65.

7. Di Febo, Giuliana, «"Nuevo Estado”, nacionalcatolicismo y género», en NielFA CRISTÓBAL, Gloria (ed.), Mujeres y hombres en la España franquista..., pp. 19-44 y «La Cuna, la Cruz y la Bandera'. Primer franquismo y modelos de género», en MORANT, Isabel (dir.), Historia de las mujeres en España y América Latina, Madrid, 2005, pp. 217-237.

8. NiCOLÁS MARÍN, Encarna y LÓPEZ GARCíA, Basilisa, «La situación de la mujer a través de los movimientos de apostolado seglar: la contribución a la legitimación del franquismo (1939-1956)», en Mujer y sociedad en España, 1700-1975, Madrid, 1986 (2a ed.), pp. 365-390, y BLASCO HERRANZ, Inmaculada, «Las Mujeres de Acción Católica durante el primer franquismo», en Tiempos de silencio. Actas del IV Encuentro de Investigadores del franquismo, Valencia, 1999, pp. 158-163. 
Antifascistas de la Guerra Civil, que reclamó mejoras en las condiciones de vida y de trabajo de las mujeres, pero sobre todo insistió en su implicación en la lucha contra el fascismo9. Tampoco se demandó que el discurso feminista impregnara al PCE. En esta primera época, las comunistas desempeñaron actividades fundamentales en la clandestinidad pero todavía consideradas secundarias -como enlaces, distribución de propaganda o asistencia a los presos políticos- y consiguieron un escaso reconocimiento. Además, estas tareas todavía estaban en buena cuenta vinculadas a su papel tradicional de esposa, madre o hija de militante. La prioridad concedida a la lucha contra la dictadura era asumida por la mayoría de las militantes, pues «su conciencia de género estaba claramente supeditada a su conciencia de clase $»^{10}$.

En suma, desde una perspectiva de género, se observa en ambas culturas políticas el fuerte peso de la mística de la maternidad, la subordinación de la esposa a los intereses y actividades del marido/compañero y la inexistencia de oportunidades reales para las mujeres en la toma de decisiones, ya fuera en la Iglesia o en el PCE. Primó una visión de la acción femenina como elemento auxiliar a la tarea de recristianización o de oposición antifranquista que desempeñaban los varones. Sin embargo, las diferencias ideológicas eran patentes, lo cual tendrá trascendencia y, como señala Mercedes Yusta, muchas de las mujeres de la resistencia interpretaron su labor no sólo en términos políticos sino también como una experiencia individual liberadora ${ }^{11}$.

A partir de finales de los cincuenta y sobre todo en los sesenta y setenta, se observan notables cambios en las culturas políticas del franquismo y en cierta forma también del antifranquismo. Como indica Román Miguel González, la aparición de nuevas categorías permite nuevas formas de concebir la sociedad, explicar cambios, hacer críticas y proponer alternativas ${ }^{12}$. Así, en las culturas políticas católica y comunista, algunos conceptos cambiaron de significado, surgieron otros nuevos y se reformularon las identidades femeninas católica y comunista, por la aparición de una nueva cultura política católica que incorporaba planteamientos igualitarios y por la evolución de la cultura comunista, en una doble dirección: por la moderación de posiciones del PCE

9. Como se refleja en NASH, Mary, Rojas. Las mujeres republicanas en la guerra civil, Madrid, 1999.

10. CABRERO, Claudia, «El PCE y las mujeres. La actitud del partido respecto a la militancia femenina durante el primer franquismo», Actas del I Congreso sobre la historia del PCE, 1920-1977, Madrid, CD-Rom, 2004, pp. 19-21.

11. YUSTA RODRIGO, Mercedes, «Rebeldía individual, compromiso familiar, acción colectiva: las mujeres en la resistencia al franquismo durante los años cuarenta», Historia del Presente, ${ }^{\circ} 4$ (2004), pp. 91-92.

12. Miguel GonZÁleZ, Román, «Las culturas políticas...», p. 213. 
y por el surgimiento de nuevos grupos de extrema izquierda. Estos dos procesos permitieron una aproximación entre católicas y comunistas, que tendrá una plasmación clara en el movimiento de mujeres de la transición.

\section{La cultura política católica y las mujeres}

Con el Concilio Vaticano II y la experiencia del apostolado obrero, se introdujeron y difundieron en España nuevos conceptos y valores -la mayoría de edad del laicado, la promoción de la mujer- y se interpretaron desde una óptica católica otros que provenían de la izquierda -igualdad, libertad, justicia-. Para Rafael Cruz, los católicos progresistas diferenciaron entre doctrina comunista -atea y materialista- y práctica -que ofrecía una posibilidad de diálogo y colaboración-, al tiempo que de forma progresiva el PCE incorporó principios democráticos como vía hacia el socialismo ${ }^{13}$. Pero también contribuyó a esa aproximación la creciente coincidencia entre experiencias y discursos de las mujeres.

En el ámbito del catolicismo, de forma paralela a la pervivencia en amplios sectores del clero y de la jerarquía del discurso católico anterior, desde la Santa Sede se promovieron nuevos planteamientos, impulsados por Juan XXIII y el Vaticano II. En esencia, este discurso conciliar insistía en la defensa de la igualdad entre los sexos, un mayor reconocimiento de las cristianas y la aceptación de los derechos fundamentales de las mujeres. Estas nuevas propuestas fueron incorporadas por los sectores más dinámicos y avanzados del clero y los seglares. Por ello Díaz-Salazar habla del desarrollo de una nueva cultura religiosa y una nueva cultura política ${ }^{14}$. En este contexto, surgió un discurso elaborado por católicas que reclamaba aplicar el principio de igualdad y la revalorización de la mujer no sólo en el matrimonio o en la sociedad, sino también en el seno de la Iglesia. Eran mujeres organizadas en Acción Católica, la Asociación de Universitarias Españolas, la Juventud de Estudiantes Católicas, la Asociación Amistad Universitaria, el Seminario de Estudios Sociológicos de la Mujer (SESM) o intelectuales como María Campo Alange, Lilí Álvarez, Pilar Bellosillo, Mary Salas o Consuelo de la Gándara, que se expresaron primero de una forma más cauta y, con el tiempo, en un interesante proceso de aprendizaje, reclamaron demandas abiertamente democráticas y

13. CruZ, Rafael, «Comunista», en FernÁndez SEBASTiÁn, Javier y FuenteS, Juan Francisco (dirs.), Diccionario político y social del siglo XX español, Madrid, 2008, pp. 272-274.

14. Díaz-SalazAr, Rafael, El factor católico en la política española. Del nacionalcatolicismo al laicismo, Madrid, 2006, p. 10. 
feministas ${ }^{15}$. También levantaron su voz obreras cristianas que militaban en HOAC y JOC o religiosas que vivieron con gran intensidad la renovación que introdujo el Vaticano II en las órdenes y congregaciones.

Estas voces femeninas influyeron en los ambientes católicos progresistas, que se vieron progresivamente impregnadas de un lenguaje marxista y, lo que más nos interesa destacar, de un vocabulario feminista. En este sentido, uno de los más prestigiosos intelectuales católicos del momento, Enrique Miret Magdalena, criticó el mito de lo femenino y la discriminación de la mujer en los textos religiosos y en la Iglesia, afirmando que la institución eclesiástica era «un puntal antifeminista» y el ambiente sociológico del momento "pariarcalista» ${ }^{16}$. La evolución del discurso católico hacia posiciones comprometidas -con límites derivados de la falta de libertades pero aprovechando cauces y foros que permitía la situación privilegiada de la Iglesia- reflejó la creciente aproximación del catolicismo progresista a la oposición antifranquista. Estos círculos católicos contribuyeron al fin de la dictadura al reivindicar una mayor justicia social y la difusión de valores democráticos ${ }^{17}$.

Un primer concepto destacado de este nuevo discurso católico es el de mujer, que se reformuló y adquirió nuevos matices. Empezó a reclamarse una mejor consideración de las mujeres en el seno de la Iglesia y en la sociedad. En una expresión muy extendida en la época, se afirmaba que la mujer había alcanzado la mayoría de edad y que era un miembro adulto de la sociedad y de la Iglesia. El SESM insistía en que la mujer española tenía que dejar de ser niña y hacerse adulta ${ }^{18}$. También entre algunas religiosas se extendió esta idea; Pilar Moriones, con gran ironía, comentaba que «el Concilio -y el Papa- nos ha incluido a nosotras, las religiosas -debe ser la primera vez en la historia-, en la categoría de personas hechas y derechas, capaces de pensar por cuenta propia ${ }^{19}$. Es decir, estas católicas reafirmaron su identidad como seres autónomos, lejos de la subordinación y paternalismo a los que habían estado sometidas hasta entonces. Por ello, frente a la anterior concepción de la mujer

15. Moreno SeCO, Mónica, «De la caridad al compromiso: las Mujeres de Acción Católica (1958-1968)», Historia Contemporánea, n 26 (2003), pp. 239-265 y «Cristianas por el socialismo y la democracia. Catolicismo femenino y movilización en los años setenta», Historia Social, no 53 (2005), pp. 137-153. Vid. también MorCiLlo, Aurora G., True Catholic Womanhood. Gender Ideology in Franco's Spain, DeKalb, 2000, pp. 159-164, y ROdRíGUEz DE LECEA, Teresa, «Mujer y pensamiento religioso en el franquismo», Ayer, $\mathrm{n}^{\circ} 17$ (1995), pp. 173-200.

16. Triunfo, 18-VII-1970, 16-IV-1977 y 29-XII-1979.

17. Montero, Feliciano, «La contribución de los Movimientos de AC a la lucha por la democracia (años sesenta)», XX Siglos, no 16 (1993), pp. 41-51.

18. Campo Alange, María (dir.), Habla la mujer, Madrid, 1967, pp. 87 y 201-202.

19. Hechos y Dichos, n 375, mayo de 1967. 
como madre y esposa, Pilar Bellosillo afirmaba que «esto ya está superado y la mujer va situándose poco a poco en la vida pública $»^{20}$. También María Salas escribió repetidas veces reclamando un proyecto de vida femenino al margen del matrimonio ${ }^{21}$.

La igualdad fue una categoría que empezó a difundirse en los grupos católicos progresistas, concepto que para las mujeres significaba un trato igualitario dentro del matrimonio, de la sociedad y de la Iglesia. Ya en 1963, en una Reunión Nacional de Mujeres de Acción Católica se afirmaba que la mujer debía ser considerada una persona con paridad de derechos y obligaciones con el hombre ${ }^{22}$. Por ello, la presidenta de esta organización, Carmen Victory, insistía en que la igualdad con el hombre en el matrimonio formaba parte de la necesaria promoción de la mujer ${ }^{23}$. A mediados de los setenta, se decía que la mujer había tomado conciencia de su dignidad como ser humano, con igualdad de derechos y deberes con el hombre ${ }^{24}$. A la vez, se exigió la igualdad en la Iglesia, criticando que se permitiera a la mujer sentirse de «tercera categoría» en dicha institución ${ }^{25}$. También entre el clero la religiosa Cecilia Collado se preguntaba: « $¿$ Encontramos aún normal la diferencia de libertad de acción entre las mujeres y los hombres consagrados? $\star^{26}$. Incluso se utiliza un lenguaje abiertamente feminista, aludiendo a la posible discriminación sexual en el cristianismo ${ }^{27}$.

En este sentido, las prevenciones de los primeros momentos ante el feminismo dieron paso con el tiempo a una identificación abierta con el movimiento de mujeres. Desde posiciones prudentes, Lilí Álvarez en 1964 vinculaba feminismo y catolicismo: «una bautizada que no fuese 'feminista' no sería una auténtica cristiana ${ }^{28}$. La evolución de estas católicas se observa con claridad en el caso de Consuelo de la Gándara, quien afirmaba en 1965 que algunas formas de emancipación femenina habían provocado graves errores de orden

20. Pilar Bellosillo, «Responsabilidades de la mujer católica en la vida social y cívica». XII Reunión Nacional de Presidentas Diocesanas, Madrid, 3-6 junio 1964: Caja 9-1-5. Archivo de la Junta Nacional de Acción Católica Española (a partir de ahora, AJNACE). Expresa opiniones similares en Vida Nueva, no 801, 9-X-1971 y Cuadernos para el Diálogo, $\mathrm{n}^{\circ}$ extraordinario XLVIII, agosto de 1975.

21. SALAS, Mary, Nosotras, las solteras, Barcelona, 1958.

22. XI Reunión Nacional de Presidentas Diocesanas, 23-26 abril 1963: Caja 9-1-4. AJNACE.

23. Circular para Dirigentes, $\mathrm{n}^{\circ} 216$, abril de 1965.

24. Entrevista a Pilar Bellosillo en Ecclesia, 7-VII-1973.

25. Mary Salas en Vida Nueva, $\mathrm{n}^{\circ}$ 659, 4-I-1969.

26. Cuaderno Informativo. CONFER Femenina, $\mathrm{n}^{\circ} 7$, julio-septiembre de 1972.

27. Propuesta de debate en Acta de 15-II-67. Actas del Pleno del Consejo, c. 1966-67: Caja 15-1-5. AJNACE.

28. ÁlvareZ, Lilí, Feminismo y espiritualidad, Madrid, 1964, p. 168. 
moral y social, pero diez años después se identificaba abiertamente con el feminismo, y señalaba que éste y la lucha de clases eran complementarios ${ }^{29}$. En los mismos términos se manifestaba Elisa Lama, que consideraba que tan importante era la lucha de clase como la lucha de sexo: «la mujer se tiene que liberar políticamente como ciudadano al mismo tiempo que como mujer. Son dos luchas que tienen que ir a la par» ${ }^{30}$. En 1972 el SESM utilizaba un lenguaje abiertamente feminista al calificar la sociedad española como patriarcal y al criticar a la mentalidad tradicional, impregnada de «la más clásica misoginia $»^{31}$.

Con las limitaciones propias del contexto de dictadura, se comenzó a reclamar la libertad de la mujer. Al principio se utilizaba la expresión «promoción de la mujer», para pedir mejoras en su educación y trabajo, y una mayor autonomía intelectual. Pero pronto se demandó la libertad: las seglares de Acción Católica se incorporaron a una campaña internacional de organizaciones católicas femeninas en 1966, en las que se pedía una libertad plena de las mujeres, para formarse, para trabajar y para «intervenir en la vida cívica del país» ${ }^{32}$.

En relación con lo anterior, hubo alusiones a una mayor participación pública de las mujeres y por tanto un apoyo implícito a la democracia. Las Mujeres de Acción Católica promovieron a partir de 1964 un plan de formación cívica de las mujeres, cuyo objetivo era convertirlas en integrantes activas de la comunidad como ciudadanas y no como súbditas, debido a que «las circunstancias actuales de España en plena evolución social pueden exigir de la mujer en un futuro próximo responsabilidades y decisiones para las que no está preparada $»^{33}$. Pilar Bellosillo reclamaba entonces que las militantes de dicha organización se implicaran en la vida pública, pues -decía- los ciudadanos debían opinar y elegir, en una clara defensa del sistema democrático ${ }^{34}$. En 1966, Carmen Victory indicó que se identificaban con los planteamientos políticos de los movimientos apostólicos obreros y estudiantiles ${ }^{35}$, es decir,

29. Cuadernos para el Diálogo, $\mathrm{n}^{\circ}$ extraordinario, diciembre de 1965 y no extraordinario XLVIII, agosto de 1975.

30. Entrevista de 1974 en Levine, Linda Gould y WALDMAn, Gloria Feiman, Feminismo ante el franquismo: entrevistas con feministas de España, Miami, 1979, pp. 120-121.

31. Mujer y aceleración histórica, Madrid, 1972, p. 22.

32. Circular para Dirigentes, enero de 1967. Actas de 17-XII-66 y 15-II-67. Actas del Pleno del Consejo, c. 1966-67: Caja 15-1-5. AJNACE.

33. Documento anejo al Acta de 25-IV-64 en Actas del Pleno, curso 1963-64: Caja 15-1-2. AJNACE.

34. XII Reunión Nacional de Presidentas Diocesanas, Madrid, 3-6 junio 1964: Caja 9-1-5. AJNACE.

35. Ecclesia, 21-V-66. 
con la crítica a la dictadura. Las Mujeres de Acción Católica, por tanto, evolucionaron ideológicamente desde el apoyo y legitimación del franquismo a la defensa de la democracia. Otras pedían una democracia interna en ámbitos eclesiásticos, como las órdenes religiosas, y reclamaban que desapareciera la actitud de privilegio del clero ${ }^{36}$.

En ocasiones se aludía a los derechos fundamentales, lo cual tenía una clara lectura política en plena dictadura. Citando a Juan XXIII y la nueva doctrina pontificia, se mencionaban, en materiales de trabajo internos o en revistas de mayor difusión como Senda, los derechos de reunión, asociación y huelga, a intervenir en la vida pública o a la seguridad jurídica, y se hacía referencia a la Declaración Universal de los Derechos Humanos ${ }^{37}$. En este discurso femenino católico, también se extendió la demanda de derechos para las mujeres, como una mejor formación y el acceso al trabajo en igualdad de condiciones con el hombre ${ }^{38}$, o el derecho a la dignidad y la autonomía ${ }^{39}$. Religiosas como Pilar Moriones o $\mathrm{M}^{\mathrm{a}}$ Teresa Ruiz-Prados exigieron derechos en la Iglesia, al respeto a sus iniciativas en el apostolado y a un mayor margen de actuación respecto a las superioras ${ }^{40}$.

Progresivamente estas católicas reclamarán abiertamente la democracia para el país y ampliarán el catálogo de derechos que consideraban básicos para las mujeres. Por ejemplo, en 1977, el SESM se planteaba como objetivos cambiar la mentalidad tradicional a través de una educación crítica, una ley del divorcio, información sobre anticonceptivos, responsabilidades familiares compartidas, la coeducación y la aplicación del principio de igual salario a igual trabajo entre hombres y mujeres, propuestas todas ellas abiertamente feministas ${ }^{41}$. Desde la Asociación de Mujeres Separadas, se denunció a los tribunales eclesiásticos y se reclamó el divorcio ${ }^{42}$. Menos unanimidad concitaron otros derechos, como la libertad sexual o el aborto. Pilar Bellosillo, que en 1965 ya comenzó a plantear del control de la natalidad, sin embargo en 1975,

36. María Teresa Ruiz-Prados en Hechos y Dichos, no 375, mayo de 1967.

37. Por una convivencia auténticamente cristiana, Madrid, 1964. Circular para Dirigentes, $\mathrm{n}^{\circ}$ 222, noviembre de 1965. Carmen Enríquez de Salamanca en su sección, Senda, n 272, junio de 1966.

38. Como hacía el SESM en Habla la mujer..., pp. 201-202 y en Mujer y aceleración histórica..., p. 7.

39. Consuelo de la Gándara en Cuadernos para el Diálogo, $\mathrm{n}^{\circ}$ extraordinario, diciembre de 1965.

40. Hechos y Dichos, no 375, mayo de 1967.

41. Salas, Mary y Comabella, Merche (coords.), «Asociaciones de mujeres y movimiento feminista», en Asociación «Mujeres en la Transición Democrática», Españolas en la transición. De excluidas a protagonistas (1973-1982), Madrid, 1999, p. 29.

42. Triunfo, 5-III-1977. 
aludiendo a la libertad sexual, manifestó su desacuerdo con la concepción individualista de la mujer que rechazaba su «dimensión humana total $»^{43}$. Las más moderadas eran contrarias al aborto, aunque, como el SESM, aceptaban los métodos anticonceptivos «de manera que cualquier mujer pudiera ejercer una maternidad responsable de acuerdo con sus propios principios éticos» ${ }^{44}$. Otras, no obstante, lo admitían en algunos casos y criticaban a la Iglesia por rechazarlo ${ }^{45}$.

Este nuevo discurso, el creciente compromiso social y la aproximación a sectores de la oposición a la dictadura dieron lugar a fuertes tensiones en el seno de la Iglesia. Las Mujeres de Acción Católica, que habían experimentado una evolución más decidida que los Hombres, se mostraron cautas ante la pretensión de la jerarquía de unir las dos organizaciones, pues «los hombres no aceptan plenamente la promoción de la mujer por la que estamos luchando $»^{46}$. Sin embargo, las trabajadoras de HOACF y JOCF colaboraron con los militantes de las organizaciones masculinas e intervinieron con ellos en la lucha obrera, probablemente porque concedieron más importancia a las demandas laborales y políticas que a las de género; sea como fuere, no alcanzaron las mismas cotas de poder dentro de la Acción Católica obrera y resulta mucho más difícil delimitar la existencia de un discurso propio ${ }^{47}$. Entre las religiosas, se consiguió que la Sección de Religiosas de la CONFER (Confederación Española de Religiosos) se convirtiera en organismo autónomo en 1968.

Cuando las esperanzas alentadas por el giro en la Santa Sede se vieron frustradas por la encíclica Humanae Vitae de Pablo VI -que definía a la mujer como madre y subordinada al varón-, el rechazo a introducir reformas en el Código Canónico que garantizaran la no discriminación de las mujeres en

43. XIII Jornadas Nacionales de Presidentas Diocesanas de Mujeres de AC, 2-4 mayo 1965: Caja 10-1-1. AJNACE. Incunable, no 310, noviembre de 1975 (cit. por SALAS LARRAZÁBAL, Mary y RODRÍGUEZ DE LECEA, Teresa, Pilar Bellosillo: nueva imagen de mujer en la Iglesia, Madrid, 2004, pp. 214-218).

44. Salas, Mary y Comabella, Merche (coords.), «Asociaciones de mujeres...», p. 28.

45. Elisa Lamas en Levine, Linda Gould y Waldman, Gloria Feiman, Feminismo ante el franquismo..., p. 111.

46. XV Jornadas Nacionales de Presidentas Diocesanas de Mujeres de AC, Madrid, 21-23 junio 1967: Caja 10-1-3. AJNACE y Circular para Dirigentes, $n^{\circ} 239$, julio-agosto de 1967.

47. Algunos testimonios aluden a «una certa por per part de les dones a ser absorbides pels homes i a no pintar res» (Testimonio de Victòria Làzaro, en FERRANDO PUIG, Emili, Cristians i Rebels. Historia de l'HOAC a Catalunya durant el franquisme (1946-1975), Barcelona, 2000, pp. 183-184). Según Antoñita Berges, «en la propia HOAC al principio los hombres eran tan machistas como todos los demás» (en ROMEU AlFaro, Fernanda, El silencio roto. Mujeres contra el franquismo, Madrid, 1994, p. 184). 
la Iglesia, la confirmación del veto al sacerdocio femenino ${ }^{48}$, o la imposición de un apostolado más controlado por el episcopado español -con la crisis de Acción Católica y la secularización de religiosas-, muchas de estas mujeres se negaron a acatar las normas de la jerarquía y continuaron ejerciendo la crítica dentro y fuera de la Iglesia. En suma, el discurso y la actividad de estas mujeres en movimientos femeninos o de base, poco valorados, no lograron transformar a la Iglesia oficial, que se resistió a aceptar unas relaciones igualitarias entre mujeres y hombres. No obstante, influyeron en otros cristianos y muchas permanecieron vinculadas a comunidades cristianas populares. Estas nuevas organizaciones de Iglesia defendían presupuestos feministas claros, aunque reconocían sus dificultades en aplicarlos ${ }^{49}$. Otras muchas abandonaron esa doble militancia para integrarse en exclusiva en plataformas sindicales, políticas, vecinales o feministas.

\section{Feminismo y mujer en las culturas políticas comunistas}

En la izquierda comunista, las categorías marxistas fueron las herramientas básicas de análisis de la realidad, pero también el lenguaje de la democracia, que poco a poco fue consolidándose, y del feminismo. Del universo de fuerzas comunistas de la época, nos centraremos en aquellas en que hubo más debate sobre los derechos de las mujeres o un mayor número de militantes con inquietudes feministas, como el PCE, el PTE (Partido del Trabajo de España) y el MC (Movimiento Comunista). Desde principios de los años setenta, el PCE se preocupó por la situación de las mujeres y pronto se mostró partidario de colaborar con el feminismo ${ }^{50}$. Por su parte, las organizaciones de la izquierda radical, aunque obtuvieron muy poco apoyo electoral, conectaron con los sectores católicos renovados y contribuyeron a difundir una visión nueva sobre

48. Vid. Bellosillo, Pilar, «La mujer en la Iglesia», en Ruiz-GimÉnEZ, Joaquín y BELLOSILLO, Pilar (coords.), El Concilio del siglo XXI. Reflexiones sobre el Vaticano II, Madrid, 1997, pp. 151-166; SALAS, María, «El papel de la mujer en la Iglesia», en DURÁN, Mª Ángeles (ed.), La mujer en el mundo contemporáneo, Madrid, 1981, pp. 99-114 y «La mujer en la Iglesia después del Concilio Vaticano II», en SÁNCHEZ, Cristina (ed.), Mujeres y hombres en la formación del pensamiento occidental, vol I. Madrid, 1989, pp. 115-122.

49. Las CCP de Cornellá recordaban en 1974 la necesaria coherencia entre la demanda de la liberación de las mujeres y las actitudes personales dentro de casa (FERNÁNDEZ SEGURA, José, La participación de los católicos en el movimiento obrero en Barcelona (19461978), Tesis doctoral defendida en la Universitat de Barcelona, 2005, pp. 644-645).

50. He abordado estos asuntos con más detalle en MORENO SECO, Mónica, «A la sombra de Pasionaria. Mujeres y militancia comunista (1960-1982)», en La historia de las mujeres: perspectivas actuales. XIII Coloquio Internacional AEIHM, 19, 20 y 21 de octubre de 2006, Barcelona, CD-Rom, 2006. 
las mujeres ${ }^{51}$. Además, el PTE y el MC evolucionaron hacia una aceptación de la democracia, la pluralidad y el pacto, en especial el primero ${ }^{52}$. Aunque podemos encontrar voces femeninas críticas, resulta difícil delimitar un discurso femenino claramente diferenciado del oficial de los partidos, si bien es un aspecto abierto a la investigación. Desde la perspectiva de género, las categorías fundamentales del lenguaje político de la izquierda marxista en los años setenta, que es la época en que las alusiones a las mujeres se multiplican, ofrecen un panorama muy interesante.

Un elemento central del discurso comunista era el concepto de pueblo, en que se integraba a las mujeres. La mayor parte de las veces no se les mencionaba, aunque en ocasiones se llamaba a la lucha a los hombres y mujeres del pueblo español o se recordaba a los hombres y mujeres que habían luchado por los intereses del pueblo ${ }^{53}$. Cuando se aludía a la mujer, ya no se hacía referencia a la esposa del camarada, sino a la compañera de lucha, en términos más igualitarios, o a la trabajadora explotada por el capitalismo. Las mujeres eran consideradas un colectivo con un gran potencial revolucionario o cuanto menos movilizador. En septiembre de 1970 el Comité Central del PCE proponía movilizar a las obreras y a las amas de casa para «utilizar a plenitud este caudal revolucionario de uno de los sectores más discriminados de nuestra sociedad $»^{54}$. Por su parte, en el discurso general del PTE, las mujeres eran un colectivo revolucionario más, que acompaña a los obreros -grupo de vanguardia-, junto con estudiantes, campesinos, soldados, intelectuales y jóvenes. Un paso más se dio ya entrados los setenta, cuando se reclamó un mayor protagonismo de las mujeres: en la campaña electoral de 1977, tuvo lugar un mitin del PCE en Madrid bajo el slogan «Partido Comunista, Mujer Protagonista $»^{55}$. Desde el PTE, Nuria Puig advertía: «no queremos que los partidos burgueses

51. LaIz, Consuelo, La lucha final. Los partidos de la izquierda radical durante la transición española, Madrid, 1995, p. 15.

52. Ibidem, pp. 245 y 267-268. Sobre estos partidos, vid. también RocA, José Manuel (ed.), El proyecto radical. Auge y declive de la izquierda revolucionaria en España (1964-1992), Madrid, 1994, pp. 50-55.

53. El Correo del Pueblo, $\mathrm{n}^{\circ}$ 9, 9-VII-1975 y no 60, 2-X-1976. Programa del MC en Ruiz, Fernando y ROMERO, Joaquín (eds.), Los partidos marxistas. Sus dirigentes, sus programas, Barcelona, 1977, p. 207.

54. Nuestra Bandera, ${ }^{\circ}$ 65, 3er trimestre de 1970.

55. En el que intervinieron Cristina Almeida, Dulcinea Bellido, Begoña San José y Mercedes Comabella (VAlverde Márquez, María José, «La mujer y el Partido Comunista de España (1958-1977)», en JimÉNEZ TOMÉ, M. J. (Coord.), Pensamiento, imagen, identidad: a la búsqueda de la definición de género, Málaga, 1999, p. 113). 
nos concedan algunas reivindicaciones», «queremos precisamente hacer política» luchando en defensa de los intereses de las mujeres ${ }^{56}$.

En estos años, la categoría igualdad era utilizada en la oposición obrera desde lenguajes de clase de ascendencia marxista y demandas cristianas de justicia social ${ }^{57}$. Para el tema que nos interesa, se insistía en la igualdad entre el hombre y la mujer ante la ley, que, como señalaba Julia Lara, del PTE, era un aspecto fundamental para las españolas «aunque no significa la igualdad ante la vida bajo el capitalismo $\star^{58}$. Por tanto se demandaba una igualdad real que fuera más allá de la formal. En su programa electoral de 1979, el PCE prometía luchar contra todas las discriminaciones y por la igualdad efectiva entre el hombre y la mujer ${ }^{59}$. En el MC, se vaticinaba que en el socialismo las relaciones entre hombres y mujeres serían de «auténtica libertad e igualdad, lo cual es muchísimo más que una simple igualdad material y jurídica ${ }^{60}$.

Vinculado a los anteriores términos, el concepto de libertad-liberación fue muy utilizado por los movimientos anticolonialistas y la teología de la liberación según Fernández Sebastián ${ }^{61}$, pero este autor olvida aludir al feminismo y a la defensa de la liberación de la mujer, muy presente en la España de los setenta. El propio PCE se denominó el partido de la liberación de la mujer en 1975 y tres años después afirmaba el MC: «los y las comunistas asumimos sin reservas la causa de la liberación de la mujer, doblemente oprimida por el capitalismo y por la dominación masculina» ${ }^{62}$.

El socialismo, como horizonte político de cambio, se presentaba como la solución a la opresión femenina, cuyo origen era atribuido, siguiendo la ortodoxia marxista, a la propiedad privada y la división de clases, es decir, al sistema capitalista ${ }^{63}$. En un primero momento se insistió en que las mujeres no conquistarían sus derechos sin el socialismo, pero más adelante se admitía que el socialismo no sería pleno sin los derechos de las mujeres. Mientras

56. El Correo del Pueblo, $\mathrm{n}^{\circ} 75,18-\mathrm{I}-1977$.

57. CRUZ ARTACHO, Salvador, «Igualdad», en FERnÁNDEZ Sebastián, Javier y FUENTES, Juan Francisco (dirs.), Diccionario político y social..., pp. 676-677.

58. El Correo del Pueblo, ${ }^{\circ}$ 46, 20-VI-1976.

59. Mundo Obrero, $\mathrm{n}^{\circ}$ 51, 18-I-1979.

60. Como afirmaba el dirigente del MC Eugenio del Río en Ruiz, Fernando y Romero, Joaquín (eds.), Los partidos marxistas..., p. 60.

61. FERnÁNDEZ SEBASTIÁN, Javier, «Libertad», en FernÁNDEZ SEbAstián, Javier y Fuentes, Juan Francisco (dirs.), Diccionario político y social..., pp. 744-745.

62. Movimiento Comunista-Organización de Izquierda Comunista: Hacia la unidad. Documentos para la preparación del Congreso Extraordinario de unificación, 1978.

63. Aunque también se atribuía la opresión femenina al fascismo (El Correo del Pueblo, $\mathrm{n}^{\circ}$ 9, 9-VII-1975) o incluso a elementos culturales e ideológicos (Eugenio del Río, del MC, en Ruiz, Fernando y Romero, Joaquín (eds.), Los partidos marxistas..., p. 58). 
otras fuerzas continuaban ancladas en el discurso más clásico, el PCE evolucionó pronto y en la II Conferencia Nacional del Partido, de 1975, se admitieron las carencias del marxismo en este aspecto y la inexistencia de una relación automática entre socialismo y liberación de la mujer ${ }^{64}$. Progresivamente se extendió la idea de que el proletariado no podía lograr la victoria completa sin conquistar la plena libertad para la mujer ${ }^{65}$, por lo que debían incorporarse a la lucha general las aportaciones del feminismo y no posponerlas para el futuro, para evitar un «socialismo de hombres y para hombres», un socialismo «a medias» ${ }^{66}$.

Resulta clarificador analizar cómo se concebía el feminismo, pues aunque durante un tiempo en algunos colectivos fue considerado un movimiento burgués que dividía a la oposición, en otros pronto se creyó importante respetarlo y apoyarlo. Por ejemplo, el PTE en 1975 defendía la tesis de que «la liberación de la mujer no vendrá de luchar contra el hombre, sino de unirse con el hombre para luchar hoy contra la dictadura», pero dos años después ya creía necesario un frente común de asociaciones feministas ${ }^{67}$. El PCE en 1975 se definió como un partido feminista ${ }^{68}$ y desde sus filas Dulcinea Bellido reclamó impregnar a todo el partido de feminismo, promover la incorporación de las trabajadoras a la actividad feminista y apoyar a los movimientos de mujeres ${ }^{69}$. También el MC demandaba un movimiento feminista independiente ${ }^{70}$. Aunque hubo algunas alusiones a un «feminismo revolucionario» en el $\mathrm{PTE}^{71}$, las propuestas concretas de este partido se limitaban a la ampliación de derechos de las mujeres en un contexto democrático.

64. ERICE Sebares, Francisco, «Mujeres comunistas. La militancia femenina en el comunismo asturiano, de los orígenes al final del franquismo», en ERICE SEBARES, Francisco (coord.), Los comunistas en Asturias (1920-1982), Gijón, 1996, p. 341.

65. El Correo del Pueblo, no 47, 29-VI-1976.

66. Eugenio del Río, Algunos problemas de la construcción del socialismo, sf.

67. Eladio García en RUIZ, Fernando y ROMERO, Joaquín (eds.), Los partidos marxistas..., El Correo del Pueblo, $\mathrm{n}^{\circ}$ 4, 5-V-1975p. 161.

68. Mundo Obrero, $n^{\circ} 29,4^{a}$ semana de septiembre de 1975; $\mathrm{n}^{\circ} 30,1^{\text {a }}$ semana de octubre de 1975. No obstante, poco antes Teresa Pàmies consideraba importante la creación de un movimiento femenino que en su opinión no debía denominarse feminista (Cuadernos para el Diálogo, agosto de 1975).

69. Nuestra Bandera, $\mathrm{n}^{\circ}$ 90, octubre-noviembre de 1977 y Mundo Obrero, $\mathrm{n}^{\circ}$ 7, 16 a 22-II-1978.

70. En Ruiz, Fernando y Romero, Joaquín (eds.), Los partidos marxistas..., p. 58.

71. Julia Lara en El Correo del Pueblo, no 46, 20-VI-1976. Nuria Puig en El Correo del Pueblo, $\mathrm{n}^{\circ} 75,18-\mathrm{I}-1977$. 
A partir de los años sesenta, el nuevo lenguaje de la democracia desplazó a los viejos lenguajes de la revolución y el nacionalcatolicismo ${ }^{72}$. En este contexto, en ocasiones se definía la democracia sin alusiones a las mujeres. Sin embargo, en otras se consideraba el fin de la discriminación de la mujer como elemento esencial de un régimen democrático. En el programa del PCE de 1977, se podía leer: «La democracia política y social tiene como uno de sus objetivos prioritarios la adopción de medidas efectivas contra todas las formas de discriminación de que es víctima la mujer de nuestra sociedad ${ }^{73}$. Algunas comunistas insistían en que la democracia no estaría completa hasta que no se implantaran unas relaciones igualitarias entre mujeres y hombres. Natalia Calamai, del PCE, afirmaba que con los cambios democráticos se estaba viviendo el comienzo de la plena equiparación legal entre hombre y mujer, pero que esos derechos eran insuficientes, pues creía necesario un replanteamiento de la familia, una moral nueva y distinguir entre sexualidad y procreación ${ }^{74}$.

A la demanda de derechos generales a veces se añadía la reivindicación de los derechos específicos de las mujeres -divorcio, anticonceptivos, aborto-. En enero de 1977, el Comité Central del PTE pidió una amplia y real democratización del país, que incluyera los derechos y libertades específicos reclamados por las mujeres y otros colectivos ${ }^{75}$. También se demandó la amnistía de los delitos considerados «femeninos». La Comisión para la Liberación de la Mujer del PCE exigió en octubre de 1976 el fin de la discriminación en la legislación y la amnistía para mujeres condenadas por motivos políticos o «femeninos» ${ }^{76}$. En Servir al Pueblo, revista del MC, se alzaron voces criticando al gobierno y a la oposición de izquierda por olvidar la amnistía de los delitos «propios de la mujer», denunciándose «las contradicciones de esta democracia que se permite ignorar la existencia de una tremenda opresión ejercida sobre la mitad de la población ${ }^{77}$.

Cabe preguntarse qué repercusión tuvieron estos principios y conceptos, que impregnaron la agenda de las fuerzas políticas de izquierda, en su práctica y vida interna. En algunos partidos consolidados, como el PCE, se crearon comisiones específicas que consiguieron con mayor o menor fortuna introducir reivindicaciones feministas en los programas, aunque no lograron que las

72. Fernández SebAStián, Javier, «Democracia», en Fernández SEbAstián, Javier y FuenTES, Juan Francisco (dirs.), Diccionario político y social..., pp. 353 y 355.

73. En Ruiz, Fernando y Romero, Joaquín (eds.), Los partidos marxistas..., p. 246.

74. Nuestra Bandera, $\mathrm{n}^{\circ} 88-89$, julio-agosto de 1977.

75. El Correo del Pueblo, $\mathrm{n}^{\circ} 74,13-\mathrm{I}-1977$.

76. Mundo Obrero, $\mathrm{n}^{\circ} 43,1-\mathrm{XII}-1976$.

77. Servir al Pueblo, no 84, 2a quincena de octubre de 1977. 
mujeres ocuparan puestos de responsabilidad en igualdad de condiciones con los varones. En el partido comunista se fundó la Comisión para la Cuestión Femenina o por la Liberación de la Mujer, con Dulcinea Bellido, Mercedes Comabella o Rosalía Sender, que organizó varias conferencias y encuentros de gran interés. Muchas de estas dirigentes estuvieron al frente del Movimiento Democrático de Mujeres (MDM). Por otro lado, en los años sesenta se incorporó al partido una generación de mujeres más joven, que aportó «una cultura política distinta a la de las militantes veteranas e incluso en conflicto con ella», con una actitud más autónoma ${ }^{78}$. Estas comunistas promovieron un intenso debate interno en torno a la opresión de la mujer y las relaciones con el movimiento feminista, con posiciones muy avanzadas, como hemos visto.

De forma paralela, se expresaba en el PCE una recurrente autocrítica por la escasa participación de mujeres en la militancia y en los órganos de dirección. Ya en 1975 se demandaba una «revolución en las mentalidades» en el partido, ante la constatación de que «en nuestras propias filas la discriminación de la mujer es una realidad; y de que aún muchos comunistas tienen ideas reaccionarias sobre el problema femenino ${ }^{79}$. En la misma época, Sara Iribarren criticó situaciones como la «escasa promoción a puestos de responsabilidad, subestimación de las camaradas, recelo ante su activismo, falta de costumbre de escucharlas (muchos camaradas aceptan mal una voz femenina), actitud autoritaria o en mejor de los casos 'condescendiente', supeditación de la militancia de la mujer a la del compañero, olvido de su formación, etc. ${ }^{80}$. Sin embargo, no se impulsaron medidas reales que incrementaran la presencia femenina en el partido, circunstancia que $\mathrm{M}^{\mathrm{a}}$ José Valverde explica por la prioridad concedida a la lucha contra la dictadura y la tradición del pensamiento marxista clásico que posponía la emancipación de la mujer al triunfo de la sociedad socialista ${ }^{81}$. Otros autores, como Francisco Erice o Claudia Cabrero, introducen otros elementos de interpretación como el peso de los estereotipos de género entre los militantes ${ }^{82}$. En suma, el auge del movimiento feminista y sus relaciones con el PCE enriquecieron el discurso del partido comunista y contribuyeron a cuestionar la invisibilidad de la militancia femenina, pero con pocos logros concretos en la vida interna del partido.

78. ERICE SebARES, Francisco, «Mujeres comunistas..., p. 334.

79. Mundo Obrero, $\mathrm{n}^{\circ} 32,3^{\mathrm{a}}$ semana de octubre de 1975.

80. Mundo Obrero, $\mathrm{n}^{\circ}$ 36, 10-XI-1975.

81. VALVerde MÁrQUeZ, $\mathrm{M}^{a}$ José, «La mujer y el Partido Comunista de España...», p. 115.

82. ERICE Sebares, Francisco, «Mujeres comunistas...» y CABRERo BlanCO, Claudia, «El PCE y las mujeres...». 
Aunque es un aspecto que necesitaría una investigación más detallada, puede adelantarse que en agrupaciones de extrema izquierda como el PTE o el MC destacó una cierta participación femenina y la inclusión de propuestas feministas en los programas, lo cual quizá esté en relación con la juventud de la militancia o la influencia de la nueva izquierda surgida en torno a 1968. El PTE, que experimentó una clara evolución hacia posiciones moderadas, en 1976 decía apoyar toda iniciativa que supusiera un avance en la liberación de la mujer y saludaba a la Asociación Democrática de la Mujer (ADM) como cauce de expresión y organización de las aspiraciones feministas ${ }^{83}$. Además acabó incorporando a su agenda política reivindicaciones básicas del movimiento feminista: de hecho, en el programa político del Frente Democrático de Izquierdas, una candidatura que el PTE y otros grupos se vieron obligados a crear ante su no legalización en las elecciones de 1977 -y del que también formaba parte la Federación de Asociaciones Democráticas de la Mujer-, se incluía la ley de divorcio, la igualdad plena de la mujer ante la ley, la despenalización del aborto y el uso de anticonceptivos a cargo de la Seguridad Social ${ }^{84}$. Pero también interesa conocer la opinión de las mujeres del partido -encuadradas en la ADM en su mayoría-: en 1976 Merche Soriano, dirigente de la ADM, recordaba que no se debía «olvidar nunca que NECESARIAMENTE esa lucha [por la liberación de la mujer] debe ir enmarcada en la lucha por los derechos democráticos para todo el pueblo ${ }^{85}$. Más adelante, Nuria Puig afirmaba que las organizaciones feministas debían intervenir en política pidiendo la unidad de las fuerzas de izquierda y la inclusión del programa feminista ${ }^{86}$. Sin embargo, las relaciones entre mujeres y hombres en el partido no eran horizontales: como reconocía uno de sus representantes, Eladio García, raro era el militante revolucionario que no incurría en el machismo, aunque afirmaba que se estaba haciendo un esfuerzo para que las mujeres tuvieran un mayor peso en los órganos de dirección del partido ${ }^{87}$.

El MC afirmaba en 1977 que aproximadamente un tercio de sus militantes eran mujeres. Su dirigente Eugenio del Río admitía en esas fechas que en los partidos revolucionarios se manifestaban, aunque de un modo atenuado, las situaciones de humillación, subordinación y desconsideración contra la mujer que se observaban en el resto de la sociedad, y afirmaba que dicha

83. El Correo del Pueblo, $\mathrm{n}^{\circ}$ 68, 17-XI-1976.

84. Folleto electoral Frente Democrático de Izquierdas. Unidos para vencer, sf.

85. El Correo del Pueblo, $\mathrm{n}^{\circ}$ 64, 26-X-1976.

86. El Correo del Pueblo, $n^{\circ} 80,23-\mathrm{II}-1977$.

87. En RUiz, Fernando y ROMERO, Joaquín (eds.), Los partidos marxistas..., pp. 162-163. 
situación debía corregirse ${ }^{88}$. Un año después, los Estatutos del MC señalaban que era una organización formada por «las mejores mujeres y hombres del pueblo» y garantizaban que en los congresos y comités la presencia de mujeres debía corresponder al porcentaje de las militantes ${ }^{89}$. En el programa de 1979 del MCPV-OEC, entre cuyos candidatos había numerosas mujeres, como Mari Llum Quiñonero -cabeza de lista por Alicante, de quien se resaltaba que era una luchadora por los derechos de la mujer-, se incluía un apartado «En defensa de los derechos de la mujer», con reivindicaciones básicas del feminismo y una ley que penalizara «los comportamientos machistas y discriminatorios $»^{90}$.

\section{La movilización feminista como espacio de confluencia}

En el magma cultural de la izquierda antifranquista, en que convivían católicas y comunistas, junto con mujeres de otras precedencias, la movilización feminista se convirtió en un foro de enriquecimiento y de intercambio de pareceres -junto con otros, como el vecinal o el obrero-. Desde diversas culturas políticas, compartían un vocabulario común, proveniente del lenguaje de la democracia, del marxista y del feminista. Comunistas y cristianas convergieron en actividades y propuestas del feminismo de la igualdad, que preconizaba la aceptación de la democracia y sus instituciones, y defendía la participación de las mujeres en los partidos y la política de la transición, proclamando que la lucha por la democracia debía completarse con la lucha feminista. El lenguaje más revolucionario acabó relegado al feminismo radical, que consideraba que la mujer era una clase explotada, oprimida por la clase antagónica, el hombre, en el seno del modo de producción doméstico ${ }^{91}$. En suma, contribuyeron al desarrollo de una nueva cultura política feminista ${ }^{92}$.

La confluencia entre catolicismo y oposición de izquierda se observa en dos de las principales publicaciones del momento, la católica Cuadernos para el Diálogo y la progresista Triunfo, en las que desde mediados de los años

88. Ibidem, pp. 59 y 207.

89. Movimiento Comunista-Organización de Izquierda Comunista: Hacia la unidad. Documentos para la preparación del Congreso Extraordinario de unificación, 1978.

90. MCPV-OEC. Programa electoral, 1979.

91. Entre los trabajos más recientes sobre el movimiento feminista pueden mencionarse AUguSTín PUERTA, Mercedes, Feminismo: identidad personal y lucha colectiva (Análisis del movimiento feminista español en los años 1975 a 1985), Granada, 2003; LARUMBE, M ${ }^{a}$ Ángeles, Las que dijeron no. Palabra y acción del feminismo en la Transición, Zaragoza, 2004, y NASH, Mary, Dones en transició. De la resistència política a la legitimitat feminista: les dones en la Barcelona de la Transició, Barcelona, 2007.

92. NASH, Mary, Dones en transició... 
sesenta expusieron su opinión sobre la situación de las mujeres comunistas como Natalia Calamai, Cristina Almeida, Dulcinea Bellido, Teresa Pàmies (todas ellas del PCE) o Sacramento Martí (PTE), y católicas como Consuelo de la Gándara, Pilar Bellosillo, Mary Salas, Lilí Álvarez, María Campo Alange o Mabel Pérez Serrano. También hubo colaboración, al menos puntual, en revistas como la Gaceta Feminista, de la ADM, en que escribió Mary Salas ${ }^{93}$.

La ADM, vinculada al PTE, y el MDM, próximo al PCE, se ofrecieron como espacios de lucha común a mujeres de diversa procedencia. La ADM señalaba que el feminismo debía ligarse a la lucha política y hacía propuestas avanzadas como el derecho al control del propio cuerpo ${ }^{94}$. Aunque en ocasiones utilizaba un lenguaje propio de la extrema izquierda, mantuvo posiciones moderadas y convocó actos reivindicativos abiertos a otras feministas. Por su parte, el MDM evolucionó desde la lucha antifranquista y las protestas por la carestía de la vida a posturas abiertamente feministas, cambiado su nombre por MDM-MLM (Movimiento de Liberación de la Mujer) ${ }^{95}$. Esta transformación queda patente al comparar sus programas de 1968 y 1976. En el primero, se aludía a la explotación de las estructuras capitalistas y de la mujer en el trabajo, y se demandaba la unión de mujeres «para un programa de liberación por sí mismas» y su integración en la «lucha general que está llevando a cabo todo el pueblo español contra la dictadura ${ }^{96}$. El MDM-MLM en 1976 se definía como movimiento feminista porque su objetivo era luchar contra la discriminación de la mujer y consideraba que «democracia es hoy una reivindicación política, objetivamente feminista»; en su presentación ante la prensa indicó que reclamaba libertades democráticas pero también que «las reivindicaciones femeninas no queden nunca diluidas ni postergadas en la lucha general política ${ }^{97}$. En suma, tenía un discurso ponderado que favoreció la cooperación con otras mujeres y organizaciones.

Los contactos y la participación en foros comunes y sobre todo el deseo de acabar con la discriminación legal de las mujeres bajo la dictadura condujeron

93. Gaceta Feminista, mayo de 1978.

94. Ciudadano. Dossier. Hacia la igualdad de la mujer, $\mathrm{n}^{\circ}$ 9, septiembre de 1976. La mujer y el derecho a controlar su propio cuerpo, ADM, Madrid, 1976.

95. Vid. ABAD Buil, Irene, «Movimiento Democrático de Mujeres. Un vehículo para la búsqueda de una nueva ciudadanía femenina en la transición española» y ARRIERO RANZ, Francisco, «El Movimiento Democrático de Mujeres: de la lucha antifranquista a la conciencia feminista (1964-1975)», ambos en Actes del Congrés La Transició de la dictadura franquista a la democracia, Barcelona, 2005, pp. 245-252 y 253-263.

96. Reprod. en DURÁN, Ma Ángeles (coord.), Mujeres y hombres. La formación del pensamiento igualitario, Madrid, 1993, pp. 193-203.

97. Programa en Moreno, Amparo, Mujeres en lucha. El movimiento feminista en España, Barcelona, 1977, pp. 108-114. Presentación en Triunfo, 22-V-1976. 
a la colaboración abierta en la conmemoración del Año Internacional de la Mujer en 1975. Grupos ligados al PCE, como el MDM, las Asociaciones de Amas de Casa o los Clubes de Amigos de la UNESCO comenzaron a coordinarse con organizaciones cristianas como el SESM, el Movimiento de Apostolado Seglar (MAS) o la HOAC. Consiguieron elaborar un programa común con peticiones feministas como el divorcio o la despenalización del adulterio y los anticonceptivos, pero también reclamaron los derechos de reunión, asociación, expresión y manifestación ${ }^{98}$.

Estos lazos se estrecharon con la organización y participación en las destacadas I Jornadas Nacionales por la Liberación de la Mujer, de diciembre de 1975, en que intervinieron comunistas y católicas, junto con mujeres de otras procedencias. En las conclusiones y resolución final de este encuentro, que firmaron entre otras MAS, HOAC, la Asociación de Amas de Casa Castellana, o el Club de Amigos de la UNESCO de Alicante, se reclamaba que las mujeres fueran «co-protagonistas en la importante tarea de configurar un cambio democrático en el país, conquistando una presencia real» y la restauración de derechos políticos como cauce para la liberación de la mujer ${ }^{99}$.

No obstante, en ocasiones fue patente la diversidad de posiciones. En mayo de 1976 tuvieron lugar las Jornades Catalanes de la Dona, en las que católicas vinculadas a la UMOFC se mostraron partidarias de que las feministas intervinieran en los partidos políticos, posición que compartían con las comunistas, también favorables a la doble militancia, frente a las defensoras de la militancia única. Pero les distinguía de las comunistas su defensa de la familia. Mientras la UMOFC acabó presentando una resolución alternativa al documento final del encuentro, en que rechazaba las conclusiones sobre la familia o la sexualidad y se lamentaba de los ataques a la Iglesia, el PTE afirmó que asumía el programa de las Jornades ${ }^{100}$.

En las principales campañas emprendidas por el movimiento feminista, participaron comunistas y cristianas. Con excepción de la reivindicación de una ley del aborto, en que las cristianas no se implicaron, todas colaboraron en las movilizaciones en defensa del derecho al divorcio, criticando la posición de la jerarquía eclesiástica, que creían debía respetar la libertad de los ciudadanos y las ciudadanas en un Estado aconfesional ${ }^{101}$, o en homenajes a

98. Salas, Mary y Comabella, Merche (coords.), «Asociaciones de mujeres...», p. 71.

99. Primeras Jornadas Nacionales por la Liberación de la Mujer. Conclusiones, Madrid, diciembre de 1975.

100. Jornades Catalanes de la Dona, maig 1976 (edición en castellano, 1976), pp. 238-239 y 518 .

101. «Divorcio y bendición episcopal», El País, 31-VII-1979. 
figuras como Clara Campoamor ${ }^{102}$. En el mismo sentido, el MDM, la ADM y el SESM, entre otros, aceptaron dialogar con el gobierno de la UCD, que creó la Subdirección General de la Condición Femenina, y negociar la legalización de las asociaciones feministas, de nuevo en contra de la opinión de otros grupos feministas opuestos a colaborar con las instituciones ${ }^{103}$. También coincidieron católicas y comunistas en su apoyo a la Constitución, que consideraban insuficiente en algunos aspectos pero sobre todo un marco básico para seguir avanzando en la igualdad, frente a otras corrientes feministas que rechazaron el texto constitucional ${ }^{104}$.

En suma, si bien pertenecían a universos ideológicos enfrentados en las primeras décadas de la dictadura franquista, a partir de los años sesenta católicas y comunistas relegaron sus diferencias en aras de la lucha común en defensa de los derechos de las mujeres. Dicho proceso fue posible por la renovación de las culturas políticas y el desarrollo de nuevos lenguajes sobre y de las mujeres en el catolicismo y el comunismo, que reflejan una clara evolución de planteamientos, y por los contactos y coincidencias en diversos foros y campañas feministas. En este sentido, el alto grado de consenso alcanzado entre muchas mujeres pone de relieve que la transición también se hizo en femenino.

102. La Unión del Pueblo, 7/13-III-1979.

103. Vid. la postura de María Salas (SESM) o Sacramento Martí (ADM) en Triunfo, 25-III-1978.

104. Firman un documento en este sentido mujeres como Dulcinea Bellido, Consuelo de la Gándara, Mary Salas, Mabel Pérez Serrano, Pilar Bellosillo, Sacramento Martí, Lilí Álvarez, Concha Borreguero, Dolores Ibárruri, Teresa Pàmies, Merche Comabella o Pilar Brabo (El País, 3-XII-1978). 